\title{
A GRAMÁTICA COMO TESTEMUNHA DO ETHOS DISCURSIVO PARLAMENTAR: ELE OCULTA, ELA DESVELA
}

\author{
(The grammar as a witness of the parliamentary \\ discursive ethos: he hides, she unveils)
}

Dulce Elena Coelho Barros ${ }^{1}$

(Universidade Estadual de Maringá - UEM)

\begin{abstract}
Current analysis deals with the conflict between the diferents types of feminine social representation in texts produced in the Brazilian Parliament. Selected analytic data refer to the violence which the female workers of Triangle Shirtwait shirt factory underwent. Data have been discussed according to discourse concept as discursive, social and linguistic practice. The discussions that pervade current investigation show the important role performed by linguistic and discursive categories in the argumentative construction of pronouncements. In fact, they elucidate the ideological stances of social agents involved in the social and discursive practice under focus.
\end{abstract}

Key words: parliamentary discourse; feminine social reality; grammar

\section{RESUMO}

A análise se desenvolve no confronto dos diferentes modos de apresentação da realidade social feminina em textos pronunciados no plenário da Câmara Federal. Os dados analíticos, que focalizam o atentado sofrido pelas operárias da fábrica de camisas Triangle Shirtwaist, são discutidos à luz da concepção de discurso como prática discursiva, prática social e prática linguística. As discussões que

1 Doutora em Linguística pela Universidade de Brasília, cuja tese "Argumentatividade no discurso parlamentar: do universo social feminino à gramática", defendida $\mathrm{e}$ aprovada em 2008, desdobra-se no presente artigo. 
permeiam o estudo pretendem destacar o papel desempenhado pelas categorias linguístico-discursivas na construção argumentativa dos pronunciamentos e na elucidação de posicionamentos ideológicos assumidos pelos atores sociais envolvidos na prática sócio-discursiva em foco.

Palavras-chave: discurso parlamentar, realidade social feminina, gramática.

\section{Introdução}

Este artigo, cujo enfoque encontra-se matizado por uma perspectiva do gênero social, bem como de gênero textual, tem por objetivo resgatar diferentes formas linguístico-discursivas pelas quais as relações sociais emergem na prática discursiva parlamentar. As reflexões aqui apresentadas nascem atreladas à concepção de que a organização argumentativa dos textos parlamentares é retórica (psíquico-social) por natureza. Nessa perspectiva, pode-se afirmar que a eficácia do dito depende, de um lado, da habilidade discursiva de atores sociais na utilização de estratégias linguísticas, que favoreçam o desencadeamento de uma ação persuasiva, ou dissuasiva, sobre a audiência. Por outro lado, ainda que a palavra usada não implique a intenção de convencer, existirá sempre uma influência voltada para determinadas maneiras de ver e de pensar do/da parlamentar.

O estudo incide sobre formas e funções de apresentação do feminino no contexto de textos elaborados para pronunciamentos no plenário da Câmara Federal. Uma vez que o objeto empírico de análise envolve textos produzidos para serem proferidos por deputados e deputadas, a noção retórica de ethos, - segundo a qual todo ato de manifestação linguística implica a construção de uma imagem de si -, mostra-se-nos bastante propícia ao reconhecimento de formas distintas de projeção parlamentar, o que, em condições propícias, pode incidir sobre a legitimidade parlamentar, ou sobre a realidade que deputados e deputadas venham a atualizar em seus discursos. 


\section{O gênero social: nas trilhas de um contexto histórico}

Ainda que o espaço social da prática discursiva parlamentar se nos revele como elemento propício à determinação de um estilo retórico prototípico, os estudos de Barros (2008) demonstram que, por um lado, os pronunciamentos das parlamentares, ao se voltarem para o universo social feminino, retratam de forma mais viva e contundente, as marcas da cólera, bem como da indignação, provocadas frente aos problemas sociais atravessados por questões de gênero. Enquanto, por outro lado, os parlamentares tendem a afirmar uma identidade de sujeito solidário, em cuja autoridade reside o poder de agir em prol daquelas que se lhes apresentam como pessoas desvalidas.

Resulta que, nos discursos de domínio político, a palavra pode ser vista como instrumento da política social, sobretudo, porque a mesma se realiza em um gênero que, sob o ponto de vista de seu caráter acional (Fairclough, 2003), está a serviço de propósitos ideológicos. A manifestação da palavra no espaço público do Congresso Nacional parece conferir ao enunciador certo poder regulatório sobre as relações de classe caracterizadas pelo autoritarismo social, conforme sugere Barros (2008:201).

Nessa perspectiva, busca-se atentar para o papel desempenhado pelas categorias linguístico-discursivas quando, em textos cuja titularidade pertence a deputados e deputadas, são feitas referências ao incêndio e morte das costureiras da fábrica norte-americana de camisas Triangle Shirtwaist (1857). Cabe, aqui, destacar que esse acontecimento, tantas vezes rememorado em práticas discursivas parlamentares, atesta que as mulheres, em sua grande maioria, até então limitadas ao mundo doméstico, ao adentrarem o território do trabalho e do poder masculino, não apenas entram em contato com a dura realidade desse mercado que as coloca no setor mais explorado e oprimido do proletariado, mas que, muito cedo, integram o exército social da resistência ao status quo.

Ressalte-se a maior revolução social do século XX, que desemboca na conquista do poder pelo proletariado, iniciada com jovens mulheres 
russas que, em plena guerra mundial, realizaram seu Dia das Mulheres, em 23 de fevereiro de 1917. Nesse dia, deflagrou-se a greve das tecelãs e costureiras de Petrogrado. Mulheres saíram corajosamente às ruas em manifesto contra a fome, a guerra o czarismo. No entanto, a ação direta das operárias russas não seria suficiente para colocá-las na posição de protagonista dessa revolução proletária.

Em sua clássica obra Historia da Revolução Russa, Trotsky (1933/1985) narra os fatos que atestam ter sido a revolução efetivamente inaugurada pelas mulheres russas que se lançaram em greve espontânea contra a guerra imperialista. Esse fato, no entanto, não foi capaz de alterar as sólidas referências hegemônicas, centradas na diferença e hierarquia das distinções identitárias.

\section{Aportes teórico-metodológicos}

A Análise de Discurso Crítica (ADC), com ênfase na análise do discurso textualmente orientada, voltada para a pesquisa social, nos moldes de Fairclough (2003), e as ferramentas da Linguística SistêmicoFuncional (Halliday e Mathiessen, 2004) constituem o passaporte que nos permite descrever e interpretar os textos parlamentares selecionados para estudo. Trata-se de uma perspectiva teórico-metodológica que reforça o enlace de um método de análise linguística textual com uma teoria do funcionamento social da linguagem, o que nos permite realizar um estudo que contempla a interface gramática e contexto social.

A análise discursiva textualmente orientada, ao permitir o exame de categorias linguísticas como parte integrante de seus dados, não negligencia o emprego das formas linguísticas em suas reflexões, muito pelo contrário, as mesmas são vistas como instrumentos linguísticos determinantes das relações de força e das sustentações ideológicas. O uso das formas linguísticas é visto como atividade por meio da qual são consolidados valores sociais e visões de mundo. É justamente essa tomada de posicionamento que leva a Análise de Discurso Crítica, 
enquanto teoria e método de estudo, a encarar o termo "discurso" como um tipo de prática social ou elemento constitutivo do social (Fairclough: 2001). Barros \& Silva (2008) sintetizam a proposta da ADC de articular, a um só tempo, os níveis linguístico, discursivo e ideológico-cultural, retratando o quadro analítico sugerido por Fairclough (2001) e por ele construído a partir do conceito de prática social e de suas relações com a teoria social do discurso.

Interessa-nos, neste estudo, examinar o componente acional na estrutura dos textos em análise. Busca-se, para tanto, identificar se a ausência, ou a presença, de marcadores da agência verbal afetam a força do enunciado, bem como se diferentes formas de representar linguisticamente ações, atores e eventos afetam as relações de sentido dos textos.

Uma outra categoria de destaque a ser abordada no presente estudo, que visa, portanto, lançar luz sobre as relações que se estabelecem entre o texto efetivamente produzido e as posições assumidas pelos participantes dessa prática discursiva, é a nominalização. Essa categoria linguística será abordada enquanto recurso retórico-argumentativo que auxilia na construção da imagem daqueles e daquelas que ocupam a tribuna federal tomando como fonte enunciativa um episódio que, entre outros fatores, lhes serve de gerador de significados. Nessa perspectiva, considera-se que as formas simbólicas se relacionam com o que ocorre fora da linguagem, ao mesmo tempo em que são organizadas em prol da construção do sentido ou significação lingüística. A propósito, ao conceberem a linguagem como um sistema semiótico complexo, Halliday \& Mathiessen (1999: 507-508) enquadram o termo "semiótica" numa taxionomia linear, ou numa ordem (orders of system) em que o sistema semiótico espelha o sistema social que, por sua vez, engloba os sistemas físico e biológico ${ }^{2}$.

2 Em palavras dos estudiosos, "we are treating language as a semiotic system (...). As we conceive of it, the term 'semiotic' is framed within a linear taxonomy of 'physical' - social - semiotic'; and the term 'system' is a shortened form of 'system-\&-process' (...). Why a 'linear' taxionomy ? There is an ordering among these four types of system (...) (Halliday \& Matthiessen, 1999: 507-508) 
Esse enquadre dos sistemas semióticos nos estudos discursivos (orders of semiotic stracta), tendo sido o mesmo também apresentado por Butt, Lukin \& Matthiessen (2004:267), permite observar que partindo dos traços estruturais internos das formas linguísticas, passando pelos contextos e processos socialmente estruturados, dentro dos quais as formas simbólicas estão inseridas, é possível desembocar nas redes de práticas que envolvem a vida social. Vemos, aqui, que a retomada do caráter simbólico da linguagem permite estudar o caráter simbólico dos fenômenos culturais, não menos inseridos do que a linguagem em contextos sociais estruturados.

Para conduzir a análise, dentre os milhares de textos que circulam no espaço de poder e força do Parlamento Nacional, foram selecionados sete textos, produzidos para serem proferidos no plenário da Câmara Federal, que tomam como objeto de discurso o atentado sofrido pelas costureiras da fábrica norte-americana de camisas Triangle Shirtwaist. Dentre os sete textos selecionados, foram extraídos um total de seis excertos submetidos à apreciação neste estudo ${ }^{3}$.

\section{Emergência das relações sociais}

A leitura atenta de um montante de trinta textos constitutivos da prática discursiva parlamentar em foco mostra-se suficiente para percebermos que quando, nesses textos, o objeto de discurso abrange o tema "mulher", os discursos dos/das parlamentares assumem um perfil argumentativo caracterizado pela integração de eventos passados, presentes e futuros. Tais eventos tomam parte de processos históricosociais acionados nesses textos como meio de provocar sentimentos e evocar idéias capazes de suscitar posições discursivas e ideológicas sobre o gênero feminino. Diríamos que a linguagem se organiza ou se

3 Os pronunciamentos dos/das parlamentares podem ser acessados no Portal da Câmara dos Deputados < http://www.camara.gov.br > 
orquestra para produzir significações geradas na interface das relações sociais estabelecidas entre os atores sociais dentro e fora do espaço de poder e controle da instância política.

Com base na posição assumida por Fairclough (2003:28), qual seja, a de que destacar os significados acionais, na determinação dos sentidos na linguagem, compreende focalizar as funções interpessoal e textual da linguagem, é possível afirmar que os/as parlamentares assumem em seus discursos uma posição de sujeito licenciado para se manifestar verbalmente numa tribuna parlamentar. Enquanto sujeitos de direito, eles/elas se manifestam como indivíduos que fazem uso recorrente do espaço de poder, do qual são parte constitutiva, para exercer o papel fundamental de defensor dos interesses de uma parcela específica dos sujeitos nele representados, a saber, as mulheres. Sendo essa ação social, ou, mais precisamente, essa prática social mediada pela linguagem, é possível que o código (forma) contenha informações acerca do seu uso e, conseqüentemente, dos efeitos sociais que o mesmo pode gerar. Nesse sentido, parte-se do pressuposto de que a produção social do sentido pode e deve ser buscada na superfície do enunciado, principalmente se considerarmos o sistema lingüístico como lugar de ajustes e acomodações intersubjetivas.

No montante dos sete textos selecionados para o estudo, os sujeitos enunciadores se valem de um fato histórico que, ao funcionar como instrumento gerador de sentidos ou significados, garante um efeito de prova aos seus argumentos que, dentre outros fatores, prestam-se à prática da persuasão e convencimento. A referência explícita ao atentado de 8 de março surge como manobra argumentativa proveitosa ao futuro discursivo dos textos, inclusive para a ação que se deseja desencadear. De acordo com Perelman (1999), toda a formulação de adesão a que está sujeita a argumentação ultrapassa o instante presente. Diríamos mais, essa busca incessante pela adesão visa ao controle das próprias relações sociais.

De certa forma, o domínio discursivo político exige a condução racional daquilo que se pretende demonstrar. Isso confere aos 
argumentos articulados (argumentação demonstrativa), ao longo do pronunciamento, certo rigor intelectual.

Considerando, ainda, a possibilidade de pensar a função interpessoal (estabelecimento e manutenção das relações sociais ou interpessoais/expressão das reações sociais e pessoais) da linguagem como realizadora de uma função identitária (estabelecimento de identidades sociais) e de uma função relacional (representação e negociação das relações sociais), tal como sugere Fairclough (2001:92), o que mais cabe ressaltar desses excertos são os posicionamentos sociais neles configurados.

Os/as parlamentares se autoposicionam em seus discursos como sujeitos imersos em uma sociedade que não apenas os molda sob vários aspectos, mas que os induz a determinadas ações. A perspectiva sociossemiótica de estudos da linguagem, à qual fiz menção acima, permite a não desassociação daquilo que ocorre no mundo da sua realização/atualização/materialização nos textos concretamente produzidos. Nesse passo, defendo que a seqüência de acontecimentos no mundo da vida é responsável pela produção dos textos que circulam na sociedade. A produção social do sentido não se faz independentemente daquilo que se apresenta pelo extralingüístico. Se existe algo no mundo, há um modo de fazer referências a ele no enunciado concreto, na sua forma de organização, no intralingüístico. Servem de exemplos dessa intromissão da forma no uso as escolhas - passíveis de manipulação pelo falante - de como representar ações, atores e eventos. Com isso em mente, examinemos o primeiro excerto.

\section{Excerto (1):}

(...) gostaria de abordar desta tribuna, mais uma vez, o transcurso do dia 8 de março, consagrado à luta das mulheres. Neste dia, no ano de 1857, as operárias têxteis de uma fábrica de Nova Iorque entraram em greve $e$ ocuparam o prédio para reivindicar a redução da jornada de trabalho de mais de 16 horas por dia para 10 horas. Essas operárias, que por 16 horas de trabalho, recebiam menos de um terço do salário dos homens, 


\section{foram fechadas na fábrica, a qual se incendiou, matando cerca de 130 mulheres.}

(Deputado Daniel Almeida, PCdoB-BA em 09/03/2004 - OD)

No excerto acima, a omissão de agentes que deveriam ocupar a posição de objeto gramatical em "essas operárias (experienciador semântico/sujeito gramatical) que, por 16 horas de trabalho, recebiam (de y/agente) menos de um terço do salário dos homens, foram fechadas (por y) na fábrica, a qual se incendiou, matando cerca de 130 mulheres”, confere ao enunciado um posicionamento sócio-ideológico diluído, uma vez que resulta pouco enfático, em relação ao evento em causa. Ao deixar em aberto a agência (parte do comentário do tema), possibilidade gramatical concedida pela língua, o parlamentar impinge ao enunciado um efeito de "anulação da oposição" (Eagleton, 1997:38) dominadas/ dominadores.

Ao se analisar os textos, simultaneamente, sob a égide da forma e do significado, é possível perceber que as muitas estratégias oferecidas pela língua ajudam a legitimar ou naturalizar os interesses de um grupo ou classe dominante ou, contrariamente, desnaturalizá-los. Ao se apagarem os agentes envolvidos no evento de que participam, a ênfase recai sobre o resultado da ação e não sobre o evento/acontecimento. Vejamos, ainda, que, no excerto (1), a possibilidade dada pela língua de omissão dos atores (+humano) do atentado se expressa também pelo "reflexivo" no segmento oracional "a qual se incendiou". A indeterminação do sujeito empírico se dá pela transposição da responsabilidade da ação para o próprio paciente ou experimentador da ação criminosa, "a fábrica". A intenção de não revelar os verdadeiros atores do atentado pode ser expressa por essa manobra lingüística, que permite supor um eventual desconhecimento por parte do enunciador daquele que executa a ação, ou mesmo um desinteresse em revelá-lo. Mais uma vez, o produtor do texto em foco insiste em representar o ator da ação prevista pelo verbo como elemento desconhecido. O desinteresse por parte do falante em apresentar formalmente esse ator, no contexto a partir do qual ele se 
expressa, pode ser encarado como uma tentativa de desconfiguração das relações de forças que se estabelecem entre gêneros masculino e feminino, tanto no interior quanto fora do espaço do Congresso Nacional.

A mesma forma de representar lingüisticamente a prática desse atentado contra a vida humana feminina repete-se no pronunciamento de outro parlamentar. Mais uma vez, a realidade expressa é apresentada no sistema lingüístico de representação de modo a envolver apagamentos de agentes, tal como se constata no próximo excerto.

\section{Excerto (2):}

A data de 8 de março, além de nos fazer refletir sobre a importância das mulheres em nossas vidas, sobre sua força e sua determinação, leva-nos ao passado, quando, neste mesmo dia no ano de 1857, em uma fábrica em Nova Iorque, 129 tecelãs foram queimadas e carbonizadas simplesmente por terem realizado a primeira paralisação de mulheres por melhores condições de trabalho. (Deputado Pastor Frankembergen, PTB-RR em 08/03/ 2006 - PE)

Em termos dos valores referenciais que comporta, a porção grifada do excerto (2) pode ser descrita da seguinte maneira: “(...) no ano de 1857, em uma fábrica em Nova Iorque, 129 tecelãs (experienciador semântico) foram queimadas e carbonizadas (por y/agente) simplesmente por terem realizado a primeira paralisação de mulheres por melhores condições de trabalho".

A possibilidade de esconder agentes em operações lingüísticas de predicação (veicular informações acerca dos objetos de discurso) mitiga o fato de que o ato de atentar contra a vida humana feminina envolve, de forma efetiva, patrões, possíveis autoridades masculinas ou homens de pensamento autoritário e repressivo. Isso quer dizer que, sob o ponto de vista intersubjetivo, a representação lingüística da realidade apreendida se deixa regular pelo leque de possibilidades, ou cadeia parafrástica, que o enunciador percorre para eleger a forma/conteúdo adequados à situação enunciativa a partir da qual se manifesta. Tais agentes, que 
aparecem de forma elíptica, não são retratados na superfície lingüística, por questões de natureza sócio-cognitiva do falante que não quer, não pode, não deve ou não conhece suficientemente a realidade expressa. $\mathrm{O}$ ouvinte/leitor dos textos pode não se dar conta do não preenchimento do espaço a ser ocupado pelo agente. Esse vazio semântico passa a funcionar como uma estratégia de imposição cognitiva, psicológica e memorial do referente, em tais representações. Isso, em condições propícias, pode afetar a "força do enunciado", ou seja, o seu componente acional. Não se pode pensar que a ausência de marcadores explícitos da agência verbal, ou mesmo a sua presença, seja indiferente às relações de sentido do texto. A direção argumentativa de um texto também parece ser afetada diferentemente, uma vez que a ação social que resulta de cada um desses usos estratégicos da língua é distinta.

Passemos ao excerto seguinte, cuja titularidade do texto pertence a uma parlamentar, e vejamos em que pontos a forma de gerenciamento do discurso difere da dos parlamentares.

\section{Excerto (3):}

Nós, mulheres do Brasil, conseguimos votar e ser votadas a partir de 1930. Não foi presente de nenhum Governo, mas conquista resultante de lutas de todas nós. Conseguimos o dia Internacional da Mulher, não só para comemorarmos, mas principalmente para refletirmos sobre a nossa luta histórica. Em 1847, 127 operárias foram queimadas vivas pelos patróes nos Estados Unidos. Elas lutavam pela mudança na jornada de trabalho, por direitos, por dignidade. As mulheres socialistas do mundo lutaram durante cem anos pelo Dia Internacional da Mulher, como dia de reflexão política, para marcar a luta pela ocupação de espaço em todo o mundo.

(Deputada Luci Choinacki, PT-SC em 06/03/ 2001 - GE)

No exemplo grifado, o mesmo evento é apresentado da seguinte maneira pela parlamentar: "Em 1847, 127 operárias (experienciador 
semântico) foram queimadas vivas pelos patrões (agente/objeto gramatical) nos Estados Unidos. Elas (agente/sujeito gramatical) lutavam pela mudança na jornada de trabalho, por direitos, por dignidade”.

$\mathrm{O}$ posicionamento mais engajado da parlamentar, que inclusive topicaliza o elemento "elas" no quinto período oracional, demonstra uma atitude mais persuasiva no que concerne ao fato de revelar os verdadeiros autores da atrocidade cometida contra a mulher, enquanto os parlamentares se posicionam de forma mais dissuasiva. A dissuasão a que me refiro constitui efeito de sentido que opera sobre a cena enunciativa, ou "lugares" a partir dos quais os parlamentares se posicionam no discurso acionado. Ao se manifestarem frente às colegas parlamentares e seus representantes do sexo feminino, eles buscam na constituição do discurso subsídios lingüísticos capazes de não os envolverem e tampouco comprometerem uma imagem identitária idealizada. A falta desse envolvimento provoca um efeito de esquecimento de que a prática da violência contra a mulher se faz por sujeitos concretos, de carne, osso e sangue tais como os que ocupam o espaço enunciativo de que fazem parte. De alguma maneira, sendo os praticantes do atentado ao qual se referem do sexo masculino, aquilo que se revela aos parlamentares no mundo da vida "fere" a identidade masculina. Dessa forma, contrariamente às parlamentares, em termos argumentativos, os parlamentares deixam marcas em seus textos de uma atitude mais evasiva no que se refere à representação dos envolvidos no evento posto em questão, enquanto as parlamentares buscam reforçar o feito, ou a atitude masculina.

Esses mesmos ajustes intersubjetivos que se fazem em prol da retratação contundente da realidade dos fatos, aos quais os enunciados estão sujeitos, como é de se esperar, podem ser igualmente visualizados nos discursos dos parlamentares. No entanto, pelo que foi dito até o momento, é possível perceber que a mesma linguagem que desvela, em condições propícias, também oculta. Vejamos, então, a que outras formas de ocultamentos a linguagem está a serviço no seguinte excerto extraído do pronunciamento de um parlamentar. 


\section{Excerto (4):}

(...) hoje se comemora o dia Internacional da Mulher. Tudo começou no dia 8 de março de 1857, quando centenas de mulheres corajosas e resolutas levantaram a cabeça e saíram às ruas da cidade de Nova Iorque, nos Estados Unidos, para protestar contra os baixos salários e a escravidão da jornada de trabalho de 12 horas, bem como as más condições de higiene nas fábricas de vestuário e têxteis. A reação dos homens, donos da cidade e machistas, foi mandar a polícia reprimir de forma violenta aquela ação de protesto. O respeito à mulher, à sua palavra, à sua inteligência, ao seu direito teve início naquela data. O mundo civilizado começou a ouvi-la, em sua homenagem, estabeleceu em 8 de março o Dia Internacional da Mulher.

(Deputado Dr. Heleno, PMDB-RJ em 08/03/2005 - OD)

Observe-se acima, na faixa do excerto, destacada em negrito. Mesmo que o pronunciamento implique uma qualificação negativa com relação aos atores do atentado de 8 março (machistas), é possível identificar que o parlamentar não especifica a forma de repressão aplicada, nem a natureza da violência à qual se refere. Ainda que o mesmo seja conhecedor dos detalhes sobre o atentado, haja vista que o assunto é recorrente na tribuna, não contempla as conseqüências do que chama de "ação de protesto". Observe-se, ainda, que os enunciados em destaque comportam um paralelismo por contraste, cuja polaridade negativa incide sobre a figura masculina e a positiva sobre a figura feminina, bem como um paralelismo sintático. O QUADRO 1, a seguir, pretende elucidar essa ocorrência.

Quadro 1 - Caracterização do masculino frente ao feminino

\begin{tabular}{|c|c|}
\hline Figura do homem: polaridade negativa & versus Figura da mulher: polaridade positiva \\
\hline Donos da cidade & $\mathrm{O}$ respeito à mulher \\
\hline Machistas & $\mathrm{O}$ respeito à palavra da mulher \\
\hline Repressores & O respeito à inteligência da mulher \\
\hline Incentivadores da violência & $\mathrm{O}$ respeito ao seu direito \\
\hline
\end{tabular}


Ainda que o paralelismo por contraste situe o referente mulher no pólo positivo da caracterização masculino versus feminino, a identidade feminina, sendo apresentada por meio das nominalizações, que, como se pode ver, integram o paralelismo sintático à direita do quadro, leva a crer numa idéia, aos nossos olhos, errônea de que "mulher" evoca um sentido ou valor referencial específico, a saber, "respeitabilidade”. Esse efeito de sentido se constrói em função da ilusão de objetividade referencial advinda da estratégia da nominalização. As repetidas nominalizações permitem esse procedimento argumentativo que se mostra profícuo à retratação de uma visão idealizada da realidade feminina, promovendo um distanciamento entre a situação ideal e a situação real da mulher. A despeito de ocorrências como essas, o montante de textos lidos para compor os dados do corpus deste estudo demonstram que a respeitabilidade feminina é um ideal almejado no curso das relações sociais entre mulheres e homens, logo, um fenômeno em curso. Dois de entrevista a seguir servem de contraponto a essa forma de apresentação do feminino presente no excerto (4).

1.“(...) infelizmente muitos preconceitos resistem a essa luta e ainda encontramos falta de respeito aos direitos da mulher, como a prática, por exemplo, da violência contra a mulher, em especial a violência sexual (...)"

(Deputado Neucimar Fraga, PL-ES em 08/03/2005 - OD).

2. "Aos olhos do mundo, o Brasil é um país onde não impera o respeito pelas mulheres"

(Deputada Kátia Abreu, PFL-TO em 29/09/2003 - GE).

A nominalização é, portanto, um outro elemento formal da língua que pode revelar formas distintas com que os parlamentares e as parlamentares agem pela linguagem (discursivamente), ao se manifestarem na tribuna federal. Esse fenômeno lingüístico é também encontrado nos últimos dois últimos excertos submetidos à análise. 
Do excerto (5), destaco a seguinte nominalização:

\section{Excerto (5):}

(...) Essa página da história, antecedida por um passado de luta pela conquista de direitos, de condição de convivência harmônica e livre, sem violências psicológicas, físicas e financeiras contra a mulher, foi escrita com muitos capitulos que registraram lutas e dores, inclusive alguns escritos com sangue, como o das 129 mulheres mortas durante o incêndio propositadamente provocado numa fábrica da cidade de Nova York, por protestarem por melhores salários e condições de trabalho, fato que levou à instituição do Dia Internacional da Mulher

(Deputada Zelinda Novaes, PFL-BA em 01/12/2004 - BC).

Do excerto (6), destaco a seguinte nominalização:

Excerto (6):

(...) Há exatamente 148 anos, no dia 8 de março, as operárias de uma fábrica de tecidos em Nova Iorque, nos Estados Unidos, entraram em greve. As trabalhadoras exigiam de seus patrões que a jornada diária de trabalho fosse reduzida de 16 horas para 10. É preciso acrescentar que essas operárias recebiam, por 16 horas de trabalho, um terço do salário dos homens que trabalhavam na mesma fabrica. Para dar mais força ao movimento grevista, as trabalhadoras ocuparam a fábrica. Foi então que começou o incêndio que resultou na morte de 130 mulheres

(Deputado Neucimar Fraga, do PL-ES em 08/03/2005 - OD).

A nominalização é definida por Fairclough (2001:223) como "a conversão de processos em nomes, que tem o efeito de pôr o processo em si em segundo plano”. Julgo não ser apressado dizer que esse efeito, ao qual se refere o estudioso ao caracterizar esse fenômeno linguístico, é também de natureza discursiva, já que o conteúdo presente nestas construções nominais - "o incêndio propositadamente provocado" (excerto 5) e "o incêndio que resultou na morte de 130 mulheres" (excerto 6) - é tomado como conhecido ou pressuposto por aqueles aos quais os pronunciamentos em foco são dirigidos. Os excertos em 
destaque evocam um referente cuja referência se encontra ancorada em um discurso anterior. Mais do que isso, eles constroem uma "dêixis discursiva" em cuja base se encontra uma "dêixis fundadora" que exige a memória de outros textos (Maingueneau, 1989: 41-42). Nesse sentido, do ponto de vista semântico, ao nominalizar um evento, o enunciador envolve o enunciatário de alguma maneira no seu discurso. Ele posiciona seus interlocutores frente a uma verdade previamente conhecida, pública e notória. A nominalização, não podendo se fazer fora dos interdiscursos, pois é através deles que o evento assume o estatuto de referente, revela se como uma estratégia sócio-interativa e cognitiva.

A contraparte significativa de um enunciado que comporta nominalizações mostra-se intimamente ligada à memória discursiva partilhada pelos interlocutores, configurada no sintagma "o incêndio que resultou na morte de 130 mulheres”, que remete ao trágico desfecho de um evento que marcou o espaço histórico da luta das mulheres no mundo. Observe-se que, no excerto (5), retirado do pronunciamento de uma parlamentar, o circunstancial de modo "propositadamente" reveste-se de carga argumentativa, uma vez que modaliza e reforça a ação criminosa do incêndio, configurada, por sua vez, no verbo provocar. A parlamentar faz com que os olhares de seus interlocutores se voltem para os praticantes do ato de incendiar, ainda que não os explicite, haja vista a omissão do agente da passiva na construção"o incêndio propositadamente provocado”. O advérbio de modo, "propositadamente”, que gramaticalmente poderia ser encarado como uma predicação dispensável, já que o sintagma nominal seria suficiente para representar o evento, serve de garantia de uma significação capaz de engendrar um saber que, para a oradora (e mulher), não deve se perder. Ao contrário, vale a pena ser reativado na memória social. A fala da parlamentar não apenas provoca emoções, mas deixa também intervir a razão. Em sua perspectiva persuasiva, a argumentação deve mostrar a força da razão. O ajuste intersubjetivo elucidado no elemento lingüístico "propositadamente" serve de prova de que, ao falarmos, posicionamos aqueles para os quais nos dirigimos. Ao posicionar os atores do atentado como criminosos, a oradora está, a um 
só tempo, posicionando as pessoas do sexo masculino como opressoras e as do sexo feminino como oprimidas.

Por outro lado, a categoria da pressuposição, legado trazido por Ducrot (1987) para a linguística, incide sobre o conteúdo partilhado pelos interlocutores, tomado por eles como "já sabido", capaz de suscitar entre eles uma espécie de cumplicidade. É justamente a noção de pressuposto que permite enxergar na nominalização uma estratégia textual que aponta para determinada direção argumentativa. Esse futuro argumentativo, inevitavelmente, inclui um sujeito, aquele do conteúdo pressuposto, uma voz já enunciada noutro lugar. No excerto em foco, essa enunciação anterior faz parte do jogo sobre a imagem do referente, tomada como evidente ou partilhada. Para Ducrot (1987), o conteúdo pressuposto em um texto é mantido em todo o discurso subseqüente. Eis, aqui, a comprovação de que operar com elementos dessa natureza permite a elucidação das diferentes direções argumentativas assumidas pelos textos, frente a diferentes objetos de discurso, oriundos de diferentes memórias discursivas.

\section{Considerações finais}

Toda essa especulação teórico-analítica parece assentar-se no fato, aceito pelos estudiosos da linguagem, de que o ato de comunicação é um ato de troca de ideias, conhecimentos, valores e visões de mundo entre dois ou mais parceiros. Para Charaudeau (2006:195), mais do que isso, ele cria um elo social que parte de normas de comportamentos e estabelece representações necessariamente partilhadas. No entanto, é impossível interpretar ou perceber tais representações sem admitirmos a existência de um posicionamento do sujeito no discurso, isto é, sem que se leve em conta o modo pelo qual os indivíduos se posicionam em práticas discursivas, lugar de localização e entrecruzamento de subjetividades. Seguindo essa mesma linha de pensamento, Davies e Harré (1990:48) afirmam que "ao falar e agir de uma posição as pessoas estão trazendo para a situação particular suas histórias (...), de alguém 
que esteve em múltiplas posições e engajado em diferentes formas de discurso" . A manifestação lingüística espelha um auto-posicionamento do locutor, a partir do qual é possível resgatar a sua identidade social. É justamente o fato de os desvelarmos, pela linguagem, como agentes sociais que leva os parlamentares a ordenarem as informações em torno de um domínio da experiência - um crime cuja responsabilidade se atribui a indivíduos do sexo masculino - valendo-se de ocultamentos, embora isso nem sempre aconteça intencionalmente. Para as parlamentares, por sua vez, o que funciona como elemento retórico-argumentativo é justamente o não ocultamento, ou seja, o reavivamento na memória discursiva de seus interlocutores dos envolvidos no fato expresso e das reais circunstâncias em que o mesmo se deu. Cumpre destacar, portanto, o papel desempenhado pelas estratégias lingüístico-discursivas de que os locutores lançam mão na obtenção desses sentidos que não se fazem alheios a posições ideológicas distintas e, porque não, engajadoras.

Ao admitirmos que a linguagem é em grande parte responsável pela construção de sistemas de pensamento, no interior dos quais o gênero masculino desponta como machista, opressor ou arrogante, é natural que os parlamentares busquem, de alguma maneira, minimizar os efeitos desses traços sociais. Uma forma de minimizar tais efeitos é buscar na língua meios de se afastar de uma enunciação anterior (préconstruída) que o posiciona como conhecedor inconteste daquilo que se manifesta no mundo da vida.

O apagamento dos agentes envolvidos em um evento que depõe contra a figura/identidade masculina provoca esquecimentos que auxiliam na desconfiguração das relações de forças, como as que se processam entre dominados e dominadores. Esse vazio semântico prestase à despotencialização de possíveis atribuições de sentido que venham a depor, principalmente, contra os próprios parlamentares.

4 No original, "in speaking and acting from a position people are bringing to the particular situation their history as a subjective being, that is the history of one who has been in multiple positions and engaged in different forms of discourse" (Davies \& Harré, 1990:48). Tradução minha. 
De acordo com Silva (2003:68) "todo discurso é sempre materializado em texto que, por sua vez, constitui unidade semântica composta por palavras e estruturas impregnadas de sentido, as quais desempenam uma determinada função em um contexto, sempre de acordo com as atitudes daqueles que as empregam”. Nessa perspectiva, assegurados pela legitimidade institucional da prática discursiva em que se inserem, os parlamentares se esforçam para despontarem em seus discursos na forma daquilo que Fairclough (2001:121) denomina de "efeito ideológico do sujeito". Tal efeito ideológico se reveste do caráter de elemento útil à construção de uma auto-imagem positiva dos parlamentares que, ao lançarem mão de uma possibilidade concedida pela língua, não se apresentam frente aos seus pares e, principalmente, frente à parcela feminina de seus representados, sob as suas condições reais de existência.

Antes de arrematar nossas reflexões analíticas, devemos ressaltar o fato de que a linguagem está inserida em contextos sociais e culturais que se nos apresentam atravessados por posicionamentos ideológicos e desigualdades sociais. É preciso, ainda, que se atente para o fato de que os diferentes usos das formas linguísticas incorporam visões ou compreensões específicas da realidade. Portanto, as conexões existentes entre as propriedades dos textos e os processos e relações sociais não podem ser negligenciadas, sobretudo, porque é necessário que se desperte uma consciência crítica do poder que a linguagem exerce sobre os seus utentes.

O objetivo do estudo terá sido alcançado se o que foi, aqui, discutido significar uma contribuição para pesquisas futuras que venham a privilegiar o enlace entre discurso e gramática, voltado, sobretudo, para questões sociais.

Recebido em: julho de 2009 Aprovado em: setembro de 2009 decbarros@uem.br 


\section{Referências Bibliográficas}

BARROS, D. E. C. Argumentatividade no discurso parlamentar: do universo social feminino à gramática. Tese de doutorado em Lingüística (inédita). Brasília: Universidade de Brasília, 2008, 234 págs.

BARROS, D. E. C. \& SILVA, D. E. G. "Práticas linguístico-discursivas sob a lupa da Análise de Discurso Crítica”. In: Gláuks - Revista de Letras e Artes, vol.8, n.2. jul./dez., 2008, p. 124-147.

BUTT, D.; LUKIN, A. \& MATTHIESSEN, C.M.I.M. "Grammar - the first covert operation of war”. In: Discourse \& Society, 15, 2004, p. 267-290.

CHARAUDEAU, P. Discurso político. Trad. Dílson Ferreira da Cruz e Fabiana Komesu. São Paulo: Contexto, 2006.

DAVIES, B. \& HARRÉ, R. "Positioning: the discursive production of selves". In: Journal of the Theory of Social Behaviour 20 (1), 1990:48, p. 43-63.

DUCROT, Oswald. $O$ dizer e o dito. Revisão técnica da tradução: Eduardo Guimarães. Campinas: Pontes, 1987.

FAIRCLOUGH, NORMAN. Analysing discourse-textual analysis for social research. London/New York: Routledge, 2003.

FAIRCLOUGH, NORMAN. Discurso e mudança social. Coordenadora da trad. Izabel Magalhães. Brasília: Editora UnB, 2001. [Original em Inglês: Discourse and social change. Cambridge: Polity Press, 1992].

HALLIDAY \& MATHIESSEN. Construing experience through meaning. London: Continuum, 1999.

HALLIDAY, M.A.K. \& MATTHIESSEN, C. M. A. M. (Rev.) An introduction to functional grammar. 3. ed. London: Arnold, 2004.

MAINGUENEAU, D. Nouvelles tendances en analyse du discours. Paris: Hachette, 1987. [Tradução brasileira: Freda Indursky, Campinas: Pontes, 1989].

PERELMAN. Chaïm. Retóricas. São Paulo: Martins Fontes,1999.

SILVA, D. E. G. "Gramática e contexto na perspectiva funcional do discurso”. In: SILVA, D. E. G., LARA, G.M.P., MENEGAZZO, M.A. (org.). Estudos de linguagem - inter-relações e perspectivas. Campo Grande, MS: Ed. UFMS, 2003.

TROTSKY, Lev D. B. La historia de la Revolución Rusa. Traducción de Andrés Nin, Lucia Gonzalez y Luis Pastor. Tomo I. Madrid: Sarpe, 1985. 